\title{
P13suc1 Associates with a cdc2-Like Kinase in a Multimeric Cytoskeletal Complex in Squid Axoplasm
}

\author{
Megumi Takahashi, ${ }^{1,2}$ Niranjana Amin, ${ }^{1}$ Philip Grant, ${ }^{1}$ and Harish C. Pant ${ }^{1}$ \\ ${ }^{1}$ Laboratory of Neurochemistry, National Institute of Neurological Disorders and Stroke, National Institutes of Health, \\ Bethesda, Maryland, '2Department of Psychiatry, School of Medicine, Yokohama City, University, Yokohama, Japan, \\ and Marine Biological Laboratory, Woods Hole, Massachusetts
}

$\mathrm{P13}^{\text {suc1 }}$ sepharose-conjugated beads were used to extract the kinases that phosphorylate neurofilaments in the squid giant axon. Using Western blots and in vitro kinase assays, we demonstrated the presence of an active cdc2-like kinase and its putative regulators such as cyclin $E, p 13$, and p67 in axoplasm and a P13-axoplasm complex (P13-Ax). Protein kinase A (PKA) and casein kinase (CK) I and II were also found in the P13-Ax. Western blot analysis of the P13Ax also demonstrated several axonal cytoskeletal components; e.g., neurofilaments (NFs; NF 60, 70, and 220), tubulin, actin, and microtubule-associated proteins. NF 220 and tubulin were phosphorylated by the kinases in the P13-Ax. To determine whether NFs bound directly to the P13 beads, or bound indirectly by association with cdc2 kinase, a washed, axon-derived neurofilament preparation that contained NFs, PKA, CKI, and tubulin, but no cdc2-like kinase, yielded no bound proteins after incubation with $\mathrm{P13}^{\text {suor. }}$. The wash supernatant from the neurofilament preparation, however, containing the cdc2-like kinase, did yield cytoskeletal components that bound to P13 ${ }^{\text {suc1. }}$. Moreover, a bacterial-expressed cdk5 associated with $P 13$ beads was able to complex with selected cytoskeletal components in the washed neurofilament preparation. These data indicate that direct binding of P13 beads with a cdc2-like kinase could extract active multimeric complexes composed of axonal cytoskeletal proteins and kinases. Application of P13 chromatography may be useful in characterizing the network of functional interactions among cytoskeletal elements and protein kinases in neurons.

[Key words: P13 ${ }^{\text {sucl, }}$ cdc2-like kinase, cytoskeleton, neurofilament, tubulin, axon]

The cdc2 genes, identified in yeast, code for protein kinases that regulate the ccll division cyclc (Myerson et al., 1992). The $\mathrm{p} 34^{\mathrm{cdc} 2} /$ cyclin $\mathrm{B}$ complex is a key player whose activity is regulated by the product of a yeast gene, known as P13 sucl (Bailly et al., 1989; Moreno et al., 1989; Jessus et al., 1990). P13

\footnotetext{
Received April 4, 1995; revised May 10, 1995; accepted May 17, 1995.

We thank Drs. Dahmus and Draetta for kindly giving us antibodies, Dr. Sloboda for giving us purified tubulin, Dr. Mukherjee for giving plasmid pLD 101, and Dr. Shaw for giving full length cdk5 construct in PET-22b. We also thank Drs. Gainer and Albers for their advice and valuable comments and Dr. Kosaka, Department of Psychiatry, Yokohama City University, for continuous encouragement.

Correspondence should be addressed to Dr. Harish C. Pant, Laboratory of Neurochemistry, NINDS, NIH, Building 36, Room 4D20, 9000 Rockville Pike, Bethesda, MD 20892.

Copyright (C) 1995 Society for Neuroscience 0270-6474/95/156222-08\$05.00/0
}

directly binds to the $\mathrm{P} 34^{\mathrm{d} d 2} / \mathrm{cyclin} \mathrm{B}$ complex with high affinity (Brizuela et al., 1987; Draetta and Beach, 1988; Dunphy et al., 1988) and when conjugated to sepharose beads, it has been useful in isolating various cdc2 kinases from mitotic cells (Dunphy et al., 1988; Gabrielli et al., 1992; Yamashita et al., 1992). Cdc2related kinases are also present in neurons (Hellmich et al., 1992; Lew et al., 1992a,b; Mawal-Dewan et al., 1992; Shetty et al., 1993; Tsai et al., 1993). Among them, cdk5 and tau protein kinase can phosphorylate neurofilaments (NFs) and the microtubule-associated protein, tau, at KSPXK sites similar to the cdc2 kinase consensus motif (Lew et al., 1992b; Hisanaga et al., 1993; Shetty et al., 1993). Even a cdc2 kinase from starfish oocytes can phosphorylate the dephosphorylated mammalian heavy subunit of neurofilament (NF-H), which dissociates it from microtubules (Hisanaga et al., 1991).

Neurofilaments, microtubules (MTs), and microfilaments (MFs), together, form an interacting, dynamic neuronal cytoskeleton involved in axon outgrowth, axonal transport, and synaptic transmission (Leterrier et al., 1982; Hirokawa, 1991; Miyakawa et al., 1993). The relative phosphorylation states of these molecules, regulated by various protein kinases (Toru-Delbauffe et al., 1986; Wible et al., 1989; Clark and Lee, 1991) and phosphatases (Sacher et al., 1992), modulate cytoskeletal interactions and neuronal functions. However, their mechanisms of interaction are still unresolved.

To explore the mechanisms underlying the dynamics of the axonal cytoskeleton, we have used the squid giant axon because large amounts of pure axoplasm can be prepared without contamination from plasma membranes or Schwann cells (Pant et al., 1986). Squid axoplasm contains NF60, NF70, and NF220 proteins and a high molecular weight subunit (HMW); the latter two are highly phosphorylated in the axon and dephosphorylated in the cell body (Cohen et al., 1987). Among the several kinases phosphorylating NFs in squid axoplasm, casein kinase (CK) I was found to be intimately associated with isolated NFs (Floyd et al., 1991). Though this kinase can phosphorylate serine residues flanked by acidic amino acids, it does not phosphorylatc the proline-directed serine residues, such as the XSPXK/R motif that is the most common phosphorylation site in the C-terminal "tail" region of NF220 (Way et al., 1992). To determine whether squid axoplasm contained a cdc2-like kinase that can phosphorylate these sites, we used P13 conjugated beads to extract such kinases. We found that P13 associated not only with a neuronal cdc2-like kinase, but also with cytoskeletal components such as NFs, MTs, and MFs, and their associated kinases. 


\section{Materials and Methods}

Materials. P13 ${ }^{\text {*uc } 1}$ agarose conjugated beads (P13 beads) were purchased from Upstate Biotechnology Inc. (UBI; Lake Placid, NY). Antibodies (Ab); Monoclonal $\alpha$ and $\beta$ tubulin Abs, monoclonal actin $A b$, and monoclonal MAP 1A, MAP 1B, and MAP 2 Abs were purchased from Amersham (Chicago, IL). Monoclonal tau Ab was obtained from Boehringer-Mannheim (Indianapolis, IN). Monoclonal antibodies to cyclin B1 and E were obtained from Santa Cruz (Santa Cruz, CA), and a polyclonal $\mathrm{Ab}$ to $\mathrm{P} 13$ and monoclonal cyclin $\mathrm{D} 1 \mathrm{Ab}$ were from Oncogene (Cambridge, MA). Polyclonal Ab to the squid neurofilament $\mathrm{N}$-terminal peptide (NF-NT, identical in all NFs) was made in the rabbit (Grant et al., 1995). Polyclonal Abs to bovine CKI and CKII were gifts from Dr. M. Dahmus (Dahmus, 1981) and polyclonal Ab to the cdc2 kinase was a gift from Dr. G. Draetta (Draetta et al., 1987). Alkaline phosphatase-conjugated goat anti-nouse IgG, goat anti-rabbit IgG and goat anti-rat IgG were purchased from Kirkegaard \& Perry (Gaithersburg, MD).

Radioactive adenosine $5^{\prime}$-trisphosphate $\left[\gamma^{-32}\right.$ P $]$ A'l'P, with a specific activity of $7000 \mathrm{Ci} / \mathrm{mmol}$ was purchased from ICN Biomedics (Costa Mesa, CA). Tubulin was a gift from Dr. R. Sloboda (Dartmouth College). ATP, Histone (Type IIIS), dephosphorylated $\alpha$-casein, and heparin were purchased from Sigma (St. Louis, MO). Staurosporine was purchased from Kyowa (Iapan), PKA inhibitor (PKI 5-24) from Peninsula Laboratories (Belmont, $\mathrm{CA}$ ), and protein kinase $\mathrm{C}$ inhibitor (Peptide PKC 19-36) from GIBCO BRL (Grand Island, NY). All other reagents used were of analytical grade.

Preparation of the P13-axoplasm complex. Sea urchin (Arbacia) and squid (Loligo pealei) were obtained at the Marine Biological Laboratory, Woods Hole, MA. Axoplasm was extruded from giant axons of freshly decapitated squid as mentioned previously (Cohen et al., 1987). Extruded axoplasm was quickly frozen on dry ice and stored at $-80^{\circ} \mathrm{C}$ until used. Axoplasm from 30 axons $(150 \mu \mathrm{l})$ was diluted and mixed in $1 \mathrm{ml}$ of extraction buffer: PBS containing $0.5 \%$ Nonidet P-40, $1 \mathrm{~mm}$ PMSF, $1 \mu \mathrm{g} / \mathrm{ml}$ leupeptin, $5 \mu \mathrm{g} / \mathrm{ml}$ aprotinin, $5 \mathrm{mM} \mathrm{MgCl}, 10 \mathrm{~mm}$ $\beta$-phosphoglycerol and $10 \mathrm{~mm}$ potassium fluoride (KF), and homogenized. Previous studies have shown that this buffer has no effect on kinase activities (Pant et al., 1986; Brizuela et al., 1987). After centrifulgation at $10000 \times g$ at $4^{\circ} \mathrm{C}$ for $20 \mathrm{~min}$, the supernatant $(1.5 \mathrm{mg} / \mathrm{ml}$ protein) was mixed with $100 \mu \mathrm{l}$ of P13 beads prewashed in extraction buffer. After rocking at $4^{\circ} \mathrm{C}$ for $2 \mathrm{hr}$, the beads were collected by a quick spin and washed four times in PBS containing $1 \%$ Triton $\mathrm{X}$ and $10 \%$ glycerol (wash buffer). Finally, the beads were diluted in $300 \mu \mathrm{l}$ of PBS. As a control, we used albumin agarose conjugated beads (Sigma) mixed with the same amount of axoplasm and carried through the procedure as above.

Sea urchin eggs and sperm were collected after injection of animals with $0.5 \mathrm{M} \mathrm{KCl}$. The eggs were washed three times in sea water and fertilized at $16^{\circ} \mathrm{C}$ and allowed to develop for $3 \mathrm{hr}$. The cleaving eggs were collected by decanting, $5 \mathrm{ml}$ of the suspension was resuspended in $20 \mathrm{ml}$ extraction buffer and homogenized. After removal of insoluble components by centrifuging at $10000 \times g$ at $4^{\circ} \mathrm{C}$ for $30 \mathrm{~min}$, the supernatant was stored at $-80^{\circ} \mathrm{C}$ until used. The supernatant $(1 \mathrm{ml})$ was incubated with $100 \mu \mathrm{l}$ P13 beads, prewashed in extraction buffer, and treated as above.

SDS-PAGE and Western blots. SDS-PAGE was performed according to the methods of Laemmli (1970). Ten microliter samples with total protein as follows: axoplasm, $15 \mu \mathrm{g}$; P13-Ax, about $6 \mu \mathrm{g}$; P13 beads alone, about $1 \mu \mathrm{g}$; albumin-axoplasm complex, less than $1 \mu \mathrm{g}, \mathrm{P} 13-$ sea urchin embryo complex, about $6 \mu \mathrm{g}$ protein, were loaded on a $10 \%$ SDS-polyacrylamide gel. Before loading on the gel, the beads were removed by centrifugation in SDS-PAGE sample buffer. Gels were stained with $0.2 \%$ Coomassie brilliant blue $\mathrm{R}$ in $10 \%$ acetic acid, $50 \%$ methanol for $1 \mathrm{hr}$, and destained in several changes of $10 \%$ acetic acid, $50 \%$ methanol. Some gels were stained with silver as described previously (Sasse and Gallagher, 1994).

Western blots were performed after electrophoretic transfer of proteins from the $10 \%$ SDS-acrylamide gel onto PVDF membranes. The transfer was carried out for $1.5 \mathrm{hr}$ at $16^{\circ} \mathrm{C}, 150 \mathrm{~m} \Lambda$. The membrane was blocked for $2 \mathrm{hr}$ at room temperature (RT, $24^{\circ} \mathrm{C}$ ) in $20 \mathrm{~mm}$ Tris-

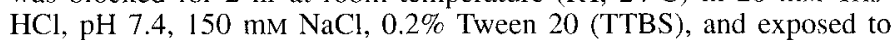
the first antibody for $2 \mathrm{hr}$ at RT. Antibodies to each of the following proteins were diluted with TTBS as follows: MAP 1A, MAP 1B, MAP 2 , Cyclin B1, DI, E, and P13, 1: 100; tau, 1:200; NF-NT, $\alpha$ and $\beta$ tubulin, actin, CKI, CKII and p67, 1:1000; cde2 kinase, 1:5000. After incubation, the membranes were washed four times in TTBS for $15 \mathrm{~min}$ each, followed by incubation in the phosphatase-labeled secondary antibody (diluted 1:2000) for $\mathrm{I} \mathrm{hr}$ at RT. The membranes were washed in TTBS four times as above and developed with 5-bromo-4-chloro-3indolyl phosphate/nitro blue tetrazolium (BCIP/NBT, Kirkegaard \& Perry).

Protein kinase activity. Protein kinase activities of the various samples (diluted P13 beads or albumin beads) were assayed according to the procedure described previously (Floyd et al., 1991). Samples $(5 \mu l$ with approximately $3 \mu \mathrm{g}$ protein) were incubated in a final total volume of $100 \mu \mathrm{l}$ containing $50 \mu \mathrm{l}$ of $2 \times$ phosphorylating buffer $(10 \mathrm{mM}$ Tris$\mathrm{HCl} \mathrm{pH}$ 7.4, 2 mM EGTA, 2 mm EDTA, $20 \mathrm{~mm} \mathrm{MgCl}_{2}, 2 \mathrm{~mm}$ DTT, and $0.2 \mu \mathrm{M}$ Okadaic acid), and $10 \mu \mathrm{l}$ of exogenous substrate (histone $\mathrm{H} 1$, casein, actin, or tubulin at $5 \mathrm{mg} / \mathrm{ml}$ ). The reaction was initiated by the addition of $10 \mu \mathrm{l}$ of $0.01 \mu \mathrm{Ci}\left[\gamma^{-32} \mathrm{P}\right] \mathrm{ATP}(500 \mu \mathrm{M})$ and incubated for $45 \mathrm{~min}$ at RT. A $40 \mu \mathrm{l}$ aliquot was removed from the incubation mixture and rapidly applied to a piece of $\mathrm{P} 81$ phosphocellulose paper. Following extensive washing of the papers in $75 \mathrm{~mm}$ phosphoric acid, ${ }^{32} \mathrm{P}$ incorporation into substrates was determined by liquid scintillation counting. In each case, the background counts (in the absence of kinase or substrates) were subtracted from the total.

For autoradiography, $10 \mu l$ of reaction mixture were analyzed by $10 \%$ SDS-PAGE. ${ }^{32} \mathrm{P}$-labeled bands were visualized by autoradiography using Kodak X-Omat AR film and intensifying screens.

Preparation of neurofilaments. Neurofilaments were prepared as previously described (Cohen et al., 1987). In brief, axoplasm from eight axons $(40 \mu \mathrm{l})$ were suspended in $500 \mu \mathrm{l}$ of $10 \mathrm{~mm}$ HEPES, $\mathrm{pH} 7.4$, $455 \mathrm{~mm} \mathrm{KF}, 1 \mathrm{~mm}$ EDTA, $1 \mathrm{~mm}$ EGTA, $1 \mathrm{~mm}$ PMSF, $1 \%$ Iriton $X$, and $10 \mu \mathrm{g} / \mathrm{ml}$ leupeptin (high-salt buffer). After $30 \mathrm{~min}$ incubation at $4^{\circ} \mathrm{C}$, NFs were pelleted by centrifugation at $10000 \times g$ for $30 \mathrm{~min}$. This pellet was called an NF preparation. The NF preparation (unwashed NFs) was washed twice with $300 \mu \mathrm{l}$ of $200 \mathrm{~mm}$ HEPES, pH 7.4, $1 \mathrm{~mm}$ PMSF, $1 \mathrm{mM}$ DTT, $10 \mu \mathrm{g} / \mathrm{ml}$ leupeptin (medium-salt buffer). After centrifugation at $10000 \times \mathrm{g}$ for $30 \mathrm{~min}$, the NF pellet (washed NFs) and supernatants were collected. The combined supernatant was called the NF wash. The NF pellet was then resuspended in $500 \mu \mathrm{l}$ of $20 \mathrm{~mm}$ Tris, pH 7.4, $1 \mathrm{~mm}$ EDTA, $1 \mathrm{~mm}$ EGTA (low-salt buffer), centrifuged at $10000 \times \mathrm{g}$ for $30 \mathrm{~min}$ at $4^{\circ} \mathrm{C}$, and the supernatant, called the NF solution, was collected. One hundred microliters of either the NF solution or NF wash was incubated with $50 \mu \mathrm{l}$ of P13 beads and $600 \mu \mathrm{l}$ of extraction buffer.

Expression and purification of $c d k 5$. Plasmid pLD101 (Mantile et al., 1993) was a gift from Dr. Mukherjee (NICHD, NIH). A full-length cdk5 (nclk) construct in PFT-2.?b was kindly provided by Dr. Shaw (University of Florida). Competent cells DH5 $\alpha^{(\mathbb{N O})}$ and BL21(DE3) were purchased from GIBCO BRL and Novagen (Madison, WI), respectively.

All recombinant DNA manipulations were performed according to standard techniques (Maniatis et al., 1982). Plasmids were prepared using Promega's Wizard Miniprep DNA purification system. Restriction enzymes, T4 DNA ligase were purchased from New England Biolabs (Beverly, MA) or Boehringer-Mannheim. The plasmid from cdk5(nclk)/PET-22b was digested with Ncol and HindIII, extracting a 950 base pair (bp) DNA fragment. This 950 bp fragment was purified and subcloned into NcoI and HindIII digested pLD101, generating pCNH101. The positive clone was transformed into BL21 (DE3) competent cells for expression.

Strain BL21 (DE3) harboring pCNH101 was grown at $37^{\circ} \mathrm{C}$ in $\mathrm{LB}$ medium supplemented with ampicillin $(50 \mu \mathrm{g} / \mathrm{ml})$ to an $\mathrm{A} 650$ at 0.5 0.6 . At this stage, isopropyl- $\beta-D$ thiogalactopyranoside (IPTG) was added at $0.45 \mathrm{~mm}$ final concentration for induction of the cdk5 gene, and cells were grown further for $3 \mathrm{hr}$ and harvested by centrifugation and the pellet was frozen at $-20^{\circ} \mathrm{C}$. The expression was checked by running the samples on $10 \%$ SDS-PAGE. The results indicated that expressed cdk5 was not in the soluble fraction but in the inclusion bodies (data not shown).

Inclusion bodies were isolated from the frozen pellet by the method of Buchner et al. (1992). Denaturing and renaturing procedures were slightly modified. The inclusion body pellet was dissolved with strong denaturant and reducing agent in a buffer containing $0.1 \mathrm{M}$ Tris, $\mathrm{pH} 8.0$ $6 \mathrm{~m}$ guanidine, $2 \mathrm{~mm}$ EDTA, $65 \mathrm{~mm}$ dithioerythrol (DTE). The solution was incubated for $2 \mathrm{hr}$ at RT and centrifuged at $30000 \times \mathrm{g}$ for $30 \mathrm{~min}$ to remove insoluble materials. The protein was renatured by rapid $100-$ fold dilution of the denatured and reduced protein into refolding buffer consisting of $0.1 \mathrm{M}$ Tris, $\mathrm{pH} 8.0,0.5 \mathrm{M} \mathrm{L}$-arginine, $0.9 \mathrm{~mm}$ GSSG (glutathione oxidized), $2 \mathrm{mM}$ ED $\mathrm{CA}$. The sample was incubated at $10^{\circ} \mathrm{C}$ for $48 \mathrm{hr}$. The refolding solution was concentrated 10 -fold and dialyzed 


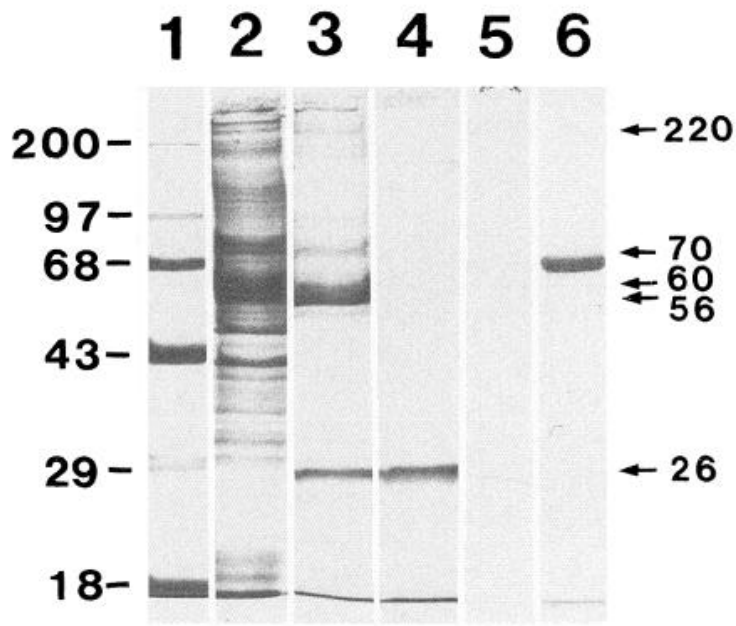

Figure 1. SDS-PAGE analysis of the P13-axoplasm complex. The P13-axoplasm complex was prepared as described in Materials and Methods. After preparing the samples for SDS-PAGE, beads were removed by centrifugation and aliquots of supernatant (equivalent to 10 $\mu \mathrm{l}$ beads) were loaded on $10 \%$ SDS-polyacrylamide gels. The gels were stained with Coomassie brilliant blue. Lane 1, Standard molecular markers; lane 2, whole axoplasm (15 $\mu$ g protein); lane 3, P13-axoplasm complex (about $6 \mu \mathrm{g}$ protein); lane 4, P13 beads only (about $1 \mu \mathrm{g}$ protein); lane 5 , albumin beads (less than $1 \mu \mathrm{g}$ protein) incubated with axoplasm (control); lane 6 , same as lane 5 except $50 \mu$ l beads were used (about $2 \mu \mathrm{g}$ protein). Arrows point to major bands that were visible in the P13-axoplasm complex.

against $20 \mathrm{~mm}$ Tris, $\mathrm{pH} 7.4,100 \mathrm{~mm}$ urea, then dialyzed gradually in $20 \mathrm{~mm}$ Tris, $\mathrm{pH} 7.4$ to remove urea.

About $50 \mu \mathrm{g}$ of purified cdk5 was incubated with $50 \mu \mathrm{l}$ P13 beads over night at $4^{\circ} \mathrm{C}$ in $500 \mu \mathrm{l}$ extraction buffer. After four washes with wash buffer, the P13 beads were collected and incubated with $100 \mu \mathrm{l}$ of the NF solution as described above.

\section{Results}

Many axoplasmic proteins bind to P13 beads

A Coomassie blue-stained gel demonstrated four major bands of $70,60,56$, and $26 \mathrm{kDa}$ in the P13-Ax (Fig. 1, lane 3). The 26 $\mathrm{kDa}$ band was derived from the P13 beads (lanes 3 and 4). We also detected moderate intensity bands of $220,190,170,96$, and $53 \mathrm{kDa}$ and very weak bands of 43,35 , and $30 \mathrm{kDa}$, that were difficult to photograph. The control albumin beads, however, did not bind any proteins under the same conditions (lane 5). Even when the amount of albumin beads was increased, we could not see any additional bands (lane 6). Lane 2 shows the protein in the axoplasm and lane 1 contains molecular weight markers.

\section{Cdc-2-like kinase is bound to the P13-axoplasm complex}

We determined whether the P13-Ax contained cdc2 kinase by Western blot analysis. As a control, we used a known source of cdc2 kinase, cleaving sea urchin embryos. In Figure 2, Western blots are shown of axoplasm, P13-axoplasm, and P13-sea urchin embryo complexes incubated with an antibody to cdc-2 kinase. A distinct $34 \mathrm{kDa}$ band can be seen in the P13-sea urchin embryo complex (lane 1), the axoplasm (lane 2), and the P13Ax (lane 3). The intensity of staining of this band in the P13Ax was greater than in the original extracts, suggesting some concentration of the kinase (lanes 2 and 3). On the other hand, albumin beads incubated with axoplasm (control) did not show any visible immunostaining band (lane 4 ). The P13 beads bound to a protein in axoplasm with the same molecular weight as cdc2 kinase and showed reactivity with antibody specific to cdc2 ki-

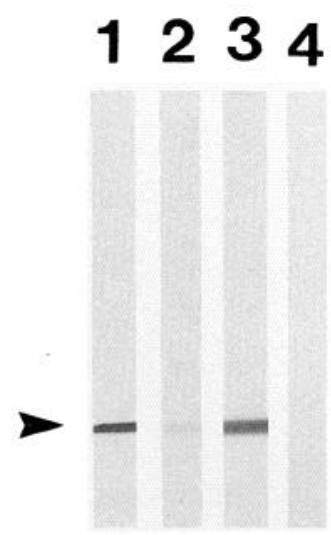

Figure 2. A Western blot of cdc2-like kinase in the P13-axoplasm complex. P13-sea urchin embryo lysate and P13-axoplasm complexes were prepared as described in Materials and Methods. Immunostaining with a cdc2 kinase Ab is shown. Lane 1, P13-sea urchin embryo complex; lane 2, axoplasm alone; lane 3, P13-axoplasm complex; lane 4, albumin-axoplasm complex (control). Arrowhead shows the cdc2 band at $34 \mathrm{kDa}$. Protein amounts per lane were the same as Figure 1.

nase. This suggested that $\mathrm{P} 13$ beads bind and concentrate a cdc2like kinase in axoplasm.

\section{Regulators of cdc2-like kinase are present in axoplasm and the P13-axoplasm complex}

Since a cdc2-like kinase that associates with P13 beads was detected in axoplasm, the question arose as to whether cyclins and/or other cyclin-dependent kinase regulators were also present in axoplasm. If so, it would suggest that cdc2-like kinase could behave as an active kinase in vivo in the axon. Accordingly, Western blots of axoplasm and the P13-Ax were performed using antibodies to cyclins B1, D1, and E. In addition, antibodies to p13 and to p67, a regulator protein of neuronal cdk-5 kinase (Shetty et al., 1995) were also tested. The results are shown in Figure 3. The p13 Ab detected a crosslinked p13 dimer $(26 \mathrm{kDa})$ in lane 1 (positive control) as well as in axoplasm (lane 2) and the P13-Ax (lane 3). Another protein of high molecular weight, sharing the p13 epitope, was also seen in the latter two lanes. Of the three cyclins tested, only bands corresponding to cyclin $\mathrm{E}$ ( $50 \mathrm{kDa}$ and $43 \mathrm{kDa}$ ) were lightly detected in axoplasm (lane 4), but more concentrated in the P13-Ax (lane 5). Additional bands (around $60 \mathrm{kDa}$ ), sharing the cyclin E epitope, were also detected in the P13-Ax. Finally, the p67 protein was also found in axoplasm and was concentrated by the P13 beads as well. It appears, therefore, that a cdc2-like kinase is present in axoplasm along with proteins known to act as cyclindependent kinase regulators. Moreover, these data suggest that the kinase and its regulator(s) form an active complex in vivo that binds to the P13 beads.

\section{Characterization of other kinases in the P13-axoplasm complex}

To further characterize the kinase in the P13-Ax, we examined its activity in vitro using histone $\mathrm{H} 1, \alpha$-casein, and tubulin as substrates (Fig. 4). We detected endogenous kinase activity (second-messenger independent), which phosphorylated 400 (HMW), 220 and $56 \mathrm{kDa}$ proteins (Fig. 4, lane 1). According to our previous studies (Pant et al., 1986; Cohen et al., 1987), the HMW and $220 \mathrm{kDa}$ proteins are squid NFs, which are mainly phosphorylated in axons, while the $56 \mathrm{kDa}$ band may be phos- 


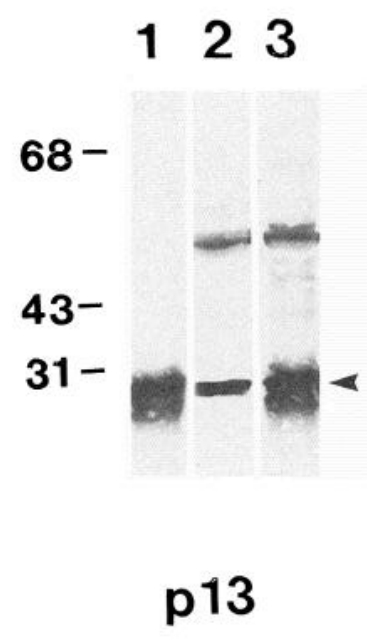

45

67

Figure 3. A Western blot analysis of putative regulators of cdc2-like kinase. Antibodies to p13, cyclins, and p67 were used to identify the putative regulators of cdc2-like kinase in axoplasm and the P13-axoplasm complex by Western blot. Lanes 1, 2, and 3, Immunostaining with anti-p13 Ab. Lane 1, P13 beads only; lane 2, axoplasm; lane 3, P13-axoplasm complex. Arrowhead points to p13 dimer of $26 \mathrm{kDa}$. Lanes 4 and 5, Immunostaining with anti-cyclin $\mathrm{E} \mathrm{Ab}$ of axoplasm (lane 4 ) and the P13-axoplasm complex (lane 5). Arrowheads point to cyclin $\mathrm{E}$ bands of $50 \mathrm{kDa}$ and $43 \mathrm{kDa}$. Lanes 6 and 7 , Immunostaining with anti-p67 Ab of axoplasm (lane 6) and the P13-axoplasm complex (lane 7). Arrowhead points to p67 band. Protein amounts per lane were the same as Figure 1.

phorylated tubulin. Western blot analysis (see below) confirmed that the $56 \mathrm{kDa}$ band was tubulin. Exogenous substrates such as histone, dephosphorylated $\alpha$-casein, and tubulin were also phosphorylated by kinase(s) associated with P13 (lanes 2, 3, and 4). Phosphorylation of the $56 \mathrm{kDa}$ band seemed to be stimulated in the presence of histone and casein. The control albumin beads did not have any kinase activities (data not shown). These data showed that the P13 beads bound to a histone H1 kinase and/or casein kinases in axoplasm that also phosphorylate NFs and tubulin. They also implied that NF proteins as well as tubulin were bound to the P13-Ax.

The kinase activity associated with the P13-Ax was characterized using various kinase inhibitors with known specificities, such as PKI (a specific inhibitor of PKA), heparin (inhibitor of CKII), and staurosporine (a PKC and cde2 kinase inhibitor). These data are shown in Table 1. Endogenous substrate phosphorylation was not affected by PKI or heparin, but staurosporine inhibited by $25 \%$. The inhibitor profile of endogenous phosphorylation suggested the presence of CKI as described in our previous study (Floyd et al., 1991). The high level of histone H1 phosphorylation by this complex was inhibited $55 \%$ by PKI and $48 \%$ by staurosporine. Phosphorylation of casein, however, showed a different pattern of inhibition; it was unaffected by PKI, inhibited only slightly by staurosporine, but showed the highest inhibition $(72 \%)$ in the presence of heparin. These data showed that more than one kinase was bound to the P13-Ax: a cdc2 kinase and a catalytic subunit of PKA that phosphorylate histone $\mathrm{H} 1$, and CKI and CKII that phosphorylate casein under the conditions of the assay.

The presence of CKI and CKII in the P13-Ax was further demonstrated in Western blots using casein kinase specific antibodies. The $35 \mathrm{kDa}$ band of CKI was detected in axoplasm and the P13-Ax, while the CKII antibody reacted moderately

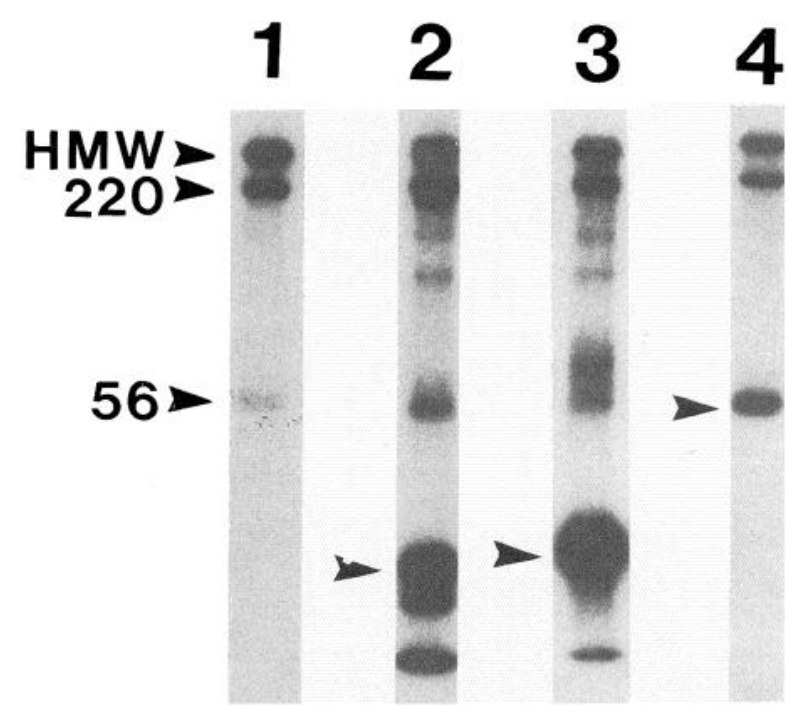

Figure 4. Autoradiographs of kinase activity in the P13-axoplasm complex. Aliquots $(5 \mu \mathrm{l})$ of the P13-axoplasm complex were incubated in the presence and absence of different substrates and $\left[\gamma-{ }^{32} \mathrm{P}\right] \mathrm{ATP}$, and autoradiography was performed after SDS-PAGE. Lane 1, Endogenous kinase activity in the P13-axoplasm complex in the absence of exogenous substrates. Arrowheads show HMW, 220 and $56 \mathrm{kDa}$ bands. Lanes 2, 3, and 4, Phosphorylation in the presence of histone, $\alpha$-casein, and tubulin, respectively. Arrowheads indicate the bands of the respective phosphorylated substrates in each lane.

with the three major bands of CKII, $50 \mathrm{kDa}, 43 \mathrm{kDa}$, and 28 $\mathrm{kDa}$ in axoplasm, and in the P13-Ax (data not shown). Note that neither kinase was more concentrated in the P13-Ax, as was the case for the cdc2-like kinase.

\section{Axonal cytoskeletal proteins are also bound to the PI3- axoplasm complex}

To characterize the remaining axoplasmic proteins binding to the P13 beads, we performed a Western blot analysis using antibodies to various cytoskeletal proteins. As shown in Figure 5, the three squid NF bands, NF220, NF70, and NF60, were detected

Table 1. Characterization of kinase activities in the P13axoplasm complex

\begin{tabular}{lcc} 
Substrate/inhibitor & $\begin{array}{l}\text { Activity } \\
(\mathrm{cpm} / 5 \mu \mathrm{l} \text { beads })\end{array}$ & \% Inhibition \\
\hline Endogenous & $2101 \pm 33$ & - \\
+ PKI $(2 \mu M)$ & $1987 \pm 65$ & 5 \\
+ staurosporine $(50 \mathrm{n} M)$ & $1577 \pm 62$ & 25 \\
$\quad$ + heparin $(5 \mu \mathrm{g} / \mathrm{ml})$ & $1758 \pm 84$ & 16 \\
Histone $(0.5 \mathrm{mg} / \mathrm{ml})$ & $26,718 \pm 1155$ & - \\
+ PKI $(2 \mu M)$ & $11,959 \pm 1450$ & 55 \\
+ staurosporine $(50 \mathrm{n} M)$ & $14,017 \pm 377$ & 48 \\
+ heparin $(5 \mu \mathrm{g} / \mathrm{ml})$ & $31,423 \pm 1243$ & $<0$ \\
$\alpha$-Casein $(0.5 \mathrm{mg} / \mathrm{ml})$ & $7400 \pm 96$ & - \\
+ PKI $(2 \mu M)$ & $7749 \pm 394$ & 0 \\
+ staurosporine $(50 \mathrm{n} M)$ & $6375 \pm 341$ & 14 \\
+ heparin $(5 \mu \mathrm{g} / \mathrm{ml})$ & $2099 \pm 68$ & 72
\end{tabular}

P13-axoplasm was suspended in $20 \mathrm{~m} M$ Tris, $\mathrm{pH} 7.4,1 \mathrm{~m} M$ EGTA, $1 \mathrm{mM}$ EDTA, $10 \mathrm{~m} M \mathrm{MgCl}_{2}, 1 \mathrm{~m} M$ DTT, $100 \mathrm{n} M$ Okadaic acid. Kinase activities in the presence and absence of specific kinase inhibitors were measured as described in Materials and Methods. Values represent the average of six measurements \pm standard error. 


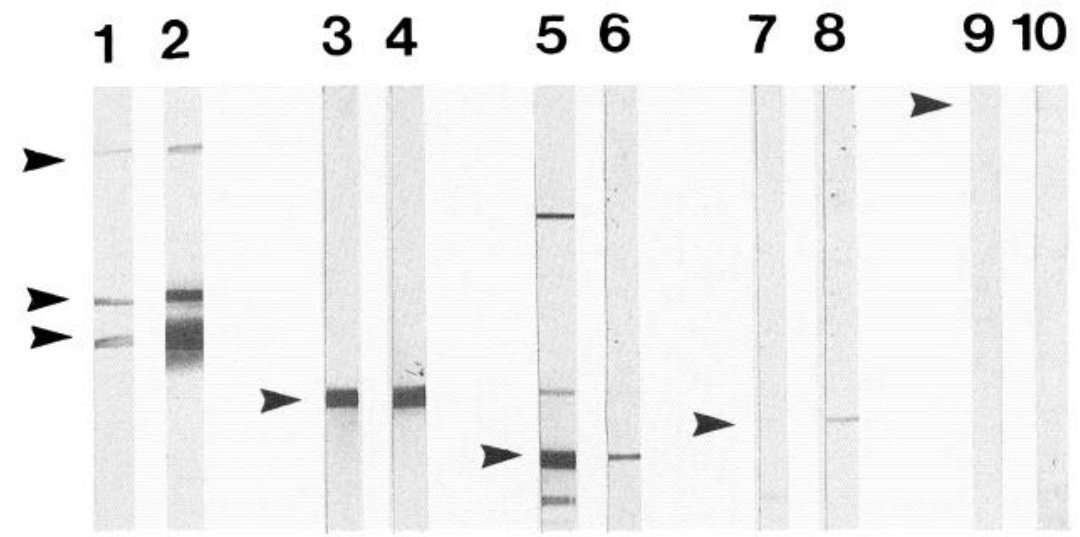

Figure 5. Identification of cytoskeletal proteins in the P13-axoplasm complex by Western blot analysis. Antibodies to neurofilaments, tubulin, actin, tau, and MAP 1A were used to identify the proteins in the P13-axoplasm complex by Western blot. Odd numbers refer to lanes with axoplasm, and even numbers identify lanes with the P13-axoplasm complex. Lanes 1 and 2, Immunostaining with anti-neurofilament N-terminal Ab. Arrowheads point to 220,70, and $60 \mathrm{kDa}$ subunits. Lanes 3 and 4, Immunostaining with anti- $\alpha$-tubulin Ab. Arrowhead at tubulin band of $56 \mathrm{kDa}$. Lanes 5 and 6. Immunostaining with anti-actin Ab. Arrowhead points to actin band of $43 \mathrm{kDa}$. Lanes 7 and 8 , Immunostaining with anti-tau Ab. Arrowhead shows tau band of $55 \mathrm{kDa}$. Lanes 9 and 10, Immunostaining with anti-MAP 1A Ab. Arrowhead points to MAP 1A band of $350 \mathrm{kDa}$. Protein amounts per lane were the same as described in Figure 1.

both in axoplasm and in the P13-Ax using the NF-NT antibody (lanes 1 and 2). These bands stained more intensely in the P13Ax than in axoplasm, indicating that the NFs had been concentrated on the beads. Monoclonal Abs to both $\alpha$ and $\beta$ tubulins reacted with the $56 \mathrm{kDa}$ bands in axoplasm and in the P13-Ax (lanes 3 and 4). In contrast to the NFs, the intensity of the tubulin bands in the P13-Ax was no greater than in axoplasm. The $43 \mathrm{kDa}$ actin band was detected in axoplasm together with other unknown protein bands (lanes 5 and 6). Unlike the NFs and tubulin, there was a reduction of actin $(43 \mathrm{kDa})$ in the P13$\mathrm{Ax}$. Tau Ab detected a band of approximately $50 \mathrm{kDa}$ both in axoplasm and the P13-Ax (lanes 7 and 8), while MAP $1 \mathrm{~A} \mathrm{Ab}$ detected what appeared to be $350 \mathrm{kDa}$ bands in axoplasm and the P13-Ax (lanes 9 and 10). Both tau and MAP 1A bands appeared to be more intensely stained in the P13-Ax. We also detected very weak immunoreactivity to MAP 1B in the P13$\mathrm{Ax}$ (data not shown). None of the proteins above were seen in immunoblots of the control albumin-axoplasm complex (data not shown).

\section{Binding of cytoskeletal proteins to $\mathrm{P} 13$ is mediated by $c d c 2$ - like kinase}

In view of the high affinity of P13 beads to cdc 2 kinase, the question arose as to how these many cytoskeletal proteins bind to the P13-Ax. Does each protein, like cdc2 kinase, bind directly and independently to the P13 beads, or do they associate indirectly by virtue of being part of a large multimeric complex containing cdc2 kinase and other kinases? To answer this question, we extracted NFs from axoplasm in high-salt buffer (NF preparation) according to a previously published procedure (Pant et al., 1986; Cohen et al., 1987; Floyd et al., 1991). This preparation was washed twice in medium-salt buffer and centrifuged. We collected the wash solution (NF wash) and resuspended the pellet in low-salt buffer. After centrifugation, the supernatant (NF solution) was loaded on a SDS-polyacrylamide gel (Fig. 6A, lane 1). This NF solution contained neurofilaments, tubulins, PKA and CKI (Pant et al., 1986; Cohen et al., 1987; Floyd et al., 1991), but no cdc2-like kinase (Fig. 6A, lane 2). The P13 beads did not bind to any protein in this NF solution (Fig. $6 A$, lane 3 ). In contrast, the NF wash contained cytoskeletal proteins
(Fig. 6A, lane 4) as well as cdc2-like kinase (Fig. 6A lane 5), and the P13 beads could extract a multimeric complex from this preparation (Fig. 6A, lane 6). These data showed that the cytoskeletal proteins would bind to the P13 beads only in the presence of cdc2-like kinase. We confirmed this hypothesis by incubating P13 beads with bacterial-expressed rat cdk5, a cdc2related kinase. Figure $6 B$, lane 1 shows purified cdk5, and lane 2 shows the cdk 5 bound to the P13 beads. In lane 3 , we see that the P13-cdk5 complex extracted several cytoskeletal proteins from the NF solution that was similar to lane 6 , Figure $6 A$. This supports the view that a cdc2-like kinase is required for formation of a multimeric complex on P13 beads.

It is also possible that the multimeric complex forms because the kinase is trapped due to low levels of ATP. The fact, however, that frozen axoplasm gave similar results as fresh axoplasm with its higher ATP levels partially mitigates this problem. Besides, in vitro experiments have shown that microtubules and neurofilaments are induced to form complexes in the presence of $1 \mathrm{~mm}$ ATP (Runge et al., 1981). If anything, exogenous ATP should favor multimeric complex formation. Until a more direct test of this question is carried out, this issue remains unresolved.

\section{Discussion}

Axoplasm from the squid giant axon contains cdc2-like kinase Several lines of evidence suggested that a cdc2-like kinase was included in the P13-Ax. First, a Western blot analysis using a polyclonal antibody to cdc 2 kinase showed the presence of an immunoreactive band at $34 \mathrm{kDa}$ in axoplasm, the P13-Ax, and the P13-sea urchin embryo complex. Second, the P13-Ax exhibited high histone $\mathrm{H} 1$ and casein phosphorylation activity in vitro, a distinctive property of cdc2 kinases (Brizuela et al., 1989). Endogenous phosphorylation as well as phosphorylation of both substrates, particularly histone $\mathrm{H1}$, was inhibited by staurosporine, a known inhibitor of cdc2 kinase (Rialet and Maijer, 1991).

Histone $\mathrm{Hl}$ is also known to be phosphorylated by other kinases such as PKC and PKA. Though staurosporine also inhibits protein kinase $\mathrm{C}(\mathrm{PKC})$, its activity would be negligible under the conditions of our kinase assay; i.e., in the presence of $1 \mathrm{~mm}$ EDTA and $1 \mathrm{mM}$ EGTA without calcium and phosphatidyl ser- 


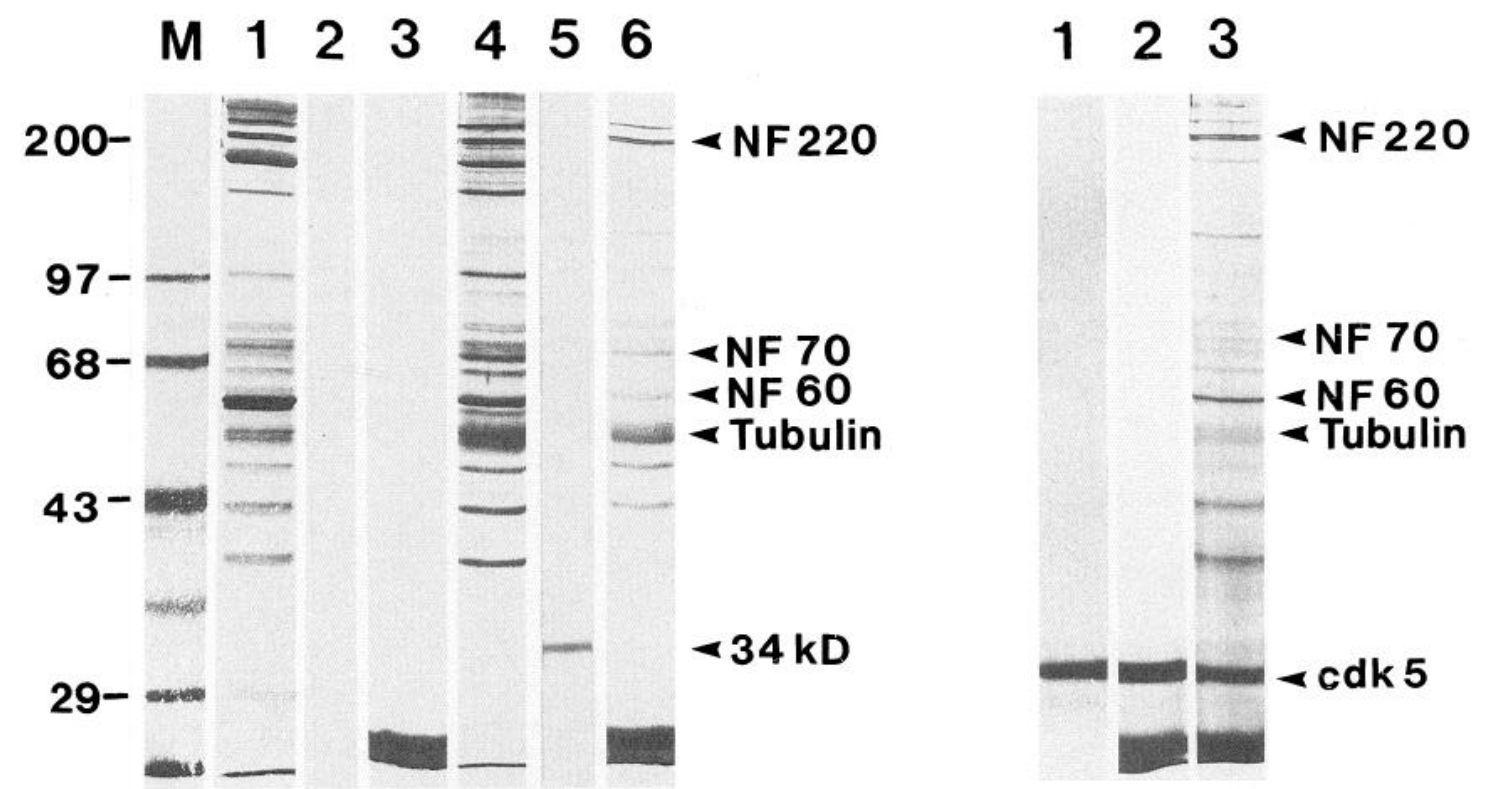

Figure 6. A, Cytoskeletal proteins in a NF preparation bind to P13 beads in the presence of cdc2-like kinase. Neurofilaments were prepared as described in Materials and Methods. This preparation was washed in medium-salt buffer and centrifuged. The supernatant was collected as an NF wash, and the pellet was resuspended in low-salt buffer, centrifuged, and the supernatant was collected as the NF solution. Both the NF solution and NF wash were incubated with P13 beads. Approximately $1 \mu \mathrm{g}$ protein of each sample was analyzed by $10 \%$ SDS-PAGE and stained with silver (lanes 1, 3, 4, and 6). Lanes 2 and 5 were Western blots to the cdc2 kinase Ab. Arrowheads show cytoskeletal components, such as NF220, NF70, NF60, tubulin, and cdc2-like kinase (34 kDa). Lanes 1 and 2, NF solution; lane 3, P13-NF solution complex; lanes 4 and 5, NF wash; lane 6, P13-NF wash complex; lane $M$, molecular weight standards. $B$, A bacterial-expressed cdk5 protein bound to P13 beads associates with cytoskeletal proteins in a NF preparation. Purified bacterial-expressed cdk5 was mixed with P13 beads and the P13-cdk5 complex was isolated. This complex was incubated in the presence of the NF solution (same as lane 1, Fig. 6A) and centrifuged. The pellet (beads) was washed as described in Materials and Methods, analyzed by $10 \%$ SDS-PAGE, and stained with silver. Lane 1, Bacterial-expressed cdk5; lane 2, P13-cdk5 complex; lane 3, P13cdk5-NF solution complex. Arrowheads show cytoskeletal components, such as NF220, NF70, NF60, tubulin, and cdk5 (32.5 kDa).

ine. Moreover, PKC inhibitor peptide had no effect on the phosphorylation of endogenous substrate or exogenously added histone $\mathrm{H} 1$ (data not shown), suggesting further that PKC was not active in the P13-Ax under our assay system.

\section{Putative regulators of cdc2-like kinase are also present in axoplasm}

The P13 beads have been used in affinity chromatography to extract active cdc2 kinase/cyclin B complexes from mitotically active cells by virtue of the affinity of p13 to cdc 2 kinase. Our data, shown in Figure 3, suggest that a functional complex of cdc2-like kinase and a putative regulator such as cyclin E and/ or p67 are also present in vivo in axoplasm. Furthermore, axoplasm contains p13 (or a p13 homologue), which is known to regulate the activity of cdc2 kinase/cyclin B complex in mitotic cells (Brizuela et al., 1987). It would appear therefore that axoplasm of nonproliferating giant fiber cells in the squid contains an active cdc2-like kinase/regulator complex that may play a role in axonal transport and/or cytoskeletal dynamics. The presence of p67 (n-Sec1/Munc-18) in axoplasm is of interest since it has been shown to be specifically localized in mammalian neural tissues, plays a role in transmitter release (Hata et al., 1993; Harrison et al., 1994; Schulze et al., 1994) and activates a neuron-specific cdk-5 kinase (Shetty et al., 1995). A neuronal cdk-5 phosphorylates NFs (Lew et al., 1992b; Shetty et al., 1993) as well as another axonal cytoskeletal protein, tau (Hisanaga et al., 1993; Paudel et al., 1994). In mammalian neuronal tissue, a p35 and/or p67 protein(s) associates with and activates this kinase (Lew et al., 1994; Tsai et al., 1994; Shetty et al., 1995). A similar multimeric complex may serve as a model for the action of the cdc2-like kinase in squid axoplasm.

\section{The P13-axoplasm complex contains other kinases}

Cdc2 kinase was not the only kinase in the P13-Ax since PKI, an inhibitor of PKA, significantly inhibited histone H1 phosphorylation without effecting the endogenous phosphorylation. The result is in agreement with our earlier studies (Pant et al., 1986). PKA is known to associate with cytoskeletal proteins such as MTs and NFs in mammalian nerve tissues (Letterier et al., 1981, Tóru-Delbauffe et al., 1986; Dosemeci et al., 1990) and in the squid axon, the PKA catalytic subunit associates with NFs (Floyd et al., 1991). Our data suggest that PKA as well as cdc2-like kinase were coextracted by P13 beads. A similar colocalization of type II cAMP kinase with cdc2 kinase was reported in fibroblast centrosomes, a region rich in microtubular protein (Tournier et al., 1991).

Other kinases were included in the P13-Ax such as CKI and CKII. Previous studies have shown that the squid axon has both CKI and CKII, which phosphorylate NF 220 (Pant et al., 1986; Link et al., 1992), but only CKI associates with NF220 (Floyd et al., 1991; Link et al., 1993). On the other hand, CKII associates with and phosphorylates tubulin (Serrano et al., 1987; Crute and Buskirk, 1992). In summary, it would appear that the P13 beads have pulled out several kinases from axoplasm, a 
cdc2-like kinase, PKA (catalytic subunit), CKI, and CKII, each capable of phosphorylating histone $\mathrm{H} 1$ or casein, as well as other endogenous substrates also associated with the P13 beads. The fact that NFs and tubulin can be phosphorylated by associated kinases implies the availability of the sites for phosphorylation in vitro. This is not surprising, inasmuch as phosphorylation/ dephosphorylation is a dynamic process in equilibrium in vivo. During the course of axoplasm extrusion and isolation, ATP will be depleted and sites will be dephosphorylated by phosphatases (Krinks et al., 1988). Furthermore, there is the evidence from mammals (Szaro et al., 1990; Elhanany et al., 1994) and squid (Cohen et al., 1987) suggesting that phosphorylation of neurofilament proteins is heterogeneous; i.e., they express different degree of phosphorylation in vivo.

\section{The P13-axoplasm complex contains several cytoskeletal} proteins

As shown in Figure 4, the P13-Ax phosphorylated endogenous substrates, the NFs (HMW and NF 220), and a $56 \mathrm{kDa}$ protein, which was identified as tubulin. Among the many proteins in axoplasm that could serve as kinase substrates, the NFs and tubulin were the predominant ones bound to the P13 beads. Intermediate filaments such as vimentin and lamins have also been shown to be substrates for P13 bound-cdc2 kinase/cyclin B in BHK-21 cells and clam oocytes, respectively (Chou et al., 1990; Dessev et al., 1991).

The SDS-PAGE and Western blot analyses confirmed the presence in the P13-Ax of all squid NFs and tubulins. In addition, other cytoskeletal proteins were detected such as actin and the microtubule associated proteins, tau, and MAP 1. These results suggested that the p13 axoplasm complex contained multimeric cytoskeletal protein complexes associated with their respective kinases.

Other observations on the association of cdc 2 kinase/cytoskeletal complexes on $\mathrm{P} 13^{\text {suc }}$ beads have been reported. A tau protein kinase isolated from a neurofilament preparation by P13 $3^{\text {suc }}$ affinity chromatography associates with neurofilaments (Mawal-Dewan et al., 1992) and dissociates NFs from MTs by phosphorylation (Hisanaga et al., 1993; Miyakawa et al., 1993). Furthermore, P13 beads isolate a cdc2 kinase/cytoskeletal complex from mitotically active yeast cells (Bailly et al., 1989), NIH 3 T3 (Zhou et al., 1992), and from skeletal muscle (Leibovitch et al., 1993).

The structure of the squid axoplasmic cytoskeletal/kinase complexes on P13 beads is not known. It is not clear whether the cdc2 kinase first binds to the P13 beads directly, with other complexes subsequently binding to the cdc2 kinase, whether cdc2 kinase is already bound to its substrates before it complexes with the P13 beads, or, whether different cytoskeletal/kinase conjugates have varying affinities and independently bind directly to the P13 beads. To distinguish among these alternatives, we showed that cytoskeletal proteins could bind P13 beads only in the presence of cdc2-like kinase or a bacterial-expressed cdk 5 . This may be analogous to the observation of a cdc 2 kinase/ cyclin B complex that associates with MTs via microtubule associated proteins in starfish oocytes (Ookata et al., 1993). At present, it is not known whether axonal cdc2-like kinase is identical to cdk-5. On the basis of their biochemical properties, they appear to be similar. If so, this means that the axonal cdc2-like kinase, like cdk-5, will have a pI of 7.62 and, as a result, a net charge of almost zero at $\mathrm{pH} 7.4$. It is therefore unlikely that the cdc2-like kinase in axoplasm acts as an ion exchanger.
The present study partially characterized the network of interactions among cytoskeletal elements and their kinases. It suggests that the components of cdc2-like kinase multimeric complexes are, indeed, present in axoplasm in vivo, organized as functional networks with the cytoskeleton, possibly involved in phosphorylation/dephosphorylation processes underlying cytoskeletal dynamics. To further explore these interactions, the following hypotheses will be entertained: (1) multimeric complexes are present in axoplasm, each containing a cdc2-like kinase, a regulator(s), and a substrate such as NF or tubulin. Each complex can bind to P13 beads independently. (2) Alternatively, each cdc2-like kinase plus regulator may be bound to a substrate (e.g., NF) which, in turn, is complexed to other cytoskeletal molecules and associated kinases (e.g., CKI, PKA, etc.) It should be noted that these hypotheses are not mutually exclusive. To characterize these complexes in vivo and in vitro, it will be necessary to examine axoplasm and the P13-Ax by high resolution electron microscopic immunocytochemistry using the appropriate antibodies.

\section{References}

Bailly E, Dor'ce M, Nurse P, Bornens M (1989) P34 $4^{\text {de2 }}$ is located in both nucleus and cytoplasm; part is centrosomally associated at G2/M and enters vesicles at anaphase. EMBO J 8:3985-3995.

Brizuela L, Draetta G, Beach D (1987) P13 ${ }^{\text {me: }}$ acts in the fission yeast cell division cycle as a component of the $\mathrm{P} 34^{\mathrm{de} 2}$ protein kinase. EMBO J 6:3507-3514.

Brizuela L, Draetta G, Beach D (1989) Activation of human CDC2 protein as a histone $\mathrm{H} 1$ kinase is associated with complex formation with the p62 subunit. Proc Natl Acad Sci USA 86:4362-4366.

Buchner J, Pastan I, Brinkmann U (1992) A method for increasing the yield of properly folded recombinant fusion proteins: single-chain immunotoxins from renaturation of bacterial inclusion bodies. Anal Biochem 205:263-270.

Chou YH, Bischoff JR, Beach D, Goldman RD (1990) Intermediate filament reorganization during mitosis is mediated by $\mathrm{P} 34^{4: k 2}$ phosphorylation of vimentin. Cell 62:1063-1671.

Clark EA, Lee VMY (1991) The differential role of protein kinase C isozymes in the rapid induction of neurofilament phosphorylation by nerve growth factor and phorbol esters in PC12 cells. J Neurochem 57: $802-810$.

Cohen RS, Pant HC, House S, Gainer H (1987) Biochemical and immunocyctochemical characterization and distribution of phosphorylated and non-phosphorylated subunits of neurofilments in squid giant axon and stellate ganglion. J Neurosci 7:2056-2074.

Crute BE, Buskirk RGV (1992) A casein kinase-like phosphorylates $\beta$-tubulin and may be a microtubule-associated protein. $J$ Neurochem 59:2017- 2023 .

Dahmus M (1981) Purification and properties of calf thymus casein kinase I and II. J Biol Chem 256:3319-3325.

Dessev G, Iovcheva-Dessev C, Bischoff JR, Beach D, Goldman R (1991) A complex containing P34 ${ }^{\mathrm{dc} 2}$ and cyclin B phosphorylates the nuclear lamin and dissembles nuclei of clam oocytes in vitro. $\mathrm{J}$ Cell Biol 112:523-533.

Dosemeci A, Floyd CC, Pant HC (1990) Characterization of neurofilament- associated protein kinase activities from bovine spinal cord. Cell Mol Neurobiol 10: 369-382.

Draetta G, Beach D (1988) Activation of cdc2 protein kinase during mitosis in human cells: cell cycle-dependent phosphorylation and subunit rearrangement. Cell 54:17-26.

Draetta G, Brizuela L, Potashkin J, Beach D (1987) Identification of p34 and p 13, human homologs of the cell cycle regulators of fission yeast encoded by $\mathrm{cdc} 2^{+}$and sucl ${ }^{+}$. Cell 50:319-325.

Dunphy WG, Brizuela L, Beach D, Newport J (1988) The Xenopus cdc2 protein is a component of NPF, a cytoplasmic regulator of mitosis. Cell 54:423-431.

Elhanany E, Jaffe H, Link WT, Sheeley DM, Gainer H, Pant HC (1994) Identification of endogenously phosphorylated KSP sites in the highmolecular-weight rat neurofilament protein. J Neurochem 63:23242335

Floyd CC, Grant P, Gallant PE, Pant HC (1991) Principal neurofila- 
ment-associated protein kinase in squid axoplasm is related to casein kinase I. J Biol Chem 266:4987-4994.

Gabrielli BG, Roy LM, Gautier J, Philippe M, Maller JL (1992) A cdc2 related kinase oscillates in the cell cycle independently of cyclin G2/M and cdc2. J Biol Chem 267:1969-1975.

Grant P, Tseng D, Gould RM, Gainer H, Pant HC (1995) Expression of neurofilament proteins during development of the nervous system in the squid Loligo pealei. J Comp Neurol 356:31 1-326.

Harrison SD, Broadie K, van de Goor J, Rubin GM (1994) Mutations in the Drosophila Rop gene suggest a function in general secretion and synaptic transmission. Neuron 13:555-566.

Hata Y, Slaughter CA, Südhof TC (1993) Synaptic vesicle fusion complex contains unc-18 homologue bound to syntaxin. Nature 366:347351

Hellmich MR, Pant HC, Wada E, Battey JF (1992) Neuronal cde2-like kinase: a cdc2-related protein kinase with predominantly neuronal expression. Proc Natl Acad Sci USA 89:10867-10871.

Hirokawa N (1991) Neurofilaments. In: The neuronal cytoskeleton (Burgoyne DR, ed), pp 5-74. New York: Wiley.

Hisanaga S, Kusubata M, Okumura E, Kishimoto T (1991) Phosphorylation of neurofilament $\mathrm{H}$ subunit at the tail domain by $\mathrm{CDC} 2$ kinase dissociates the association to microtubules. J Biol Chem 266:2179821803.

Hisanaga S, Ishiguro K, Uchida T, Okumuru E, Okano T, Kishimoto T (1993) Tau protein kinase II has a similar characteristic to cdc2 kinase for phosphorylation neurofilament proteins. J Biol Chem 268: 15056-15060.

Jessus C, Ducommun B, Beach D (1990) Direct activation of cde2 with phosphatase: identification of $\mathrm{Pl} 3^{\text {sucl }}$-sensitive and insensitive steps. FEBS Lett 266:4-8

Krinks MH, Klee CB, Pant HC, Gainer H (1988) Identification and quantification of calcium-binding protcins in squid axoplasm. J Neurosci 250:617-620.

Laemmli UK (1970) Cleavage of structural proteins during assembly of the head of bacteriophage T4. Nature 227:680-685.

Leibovitch SA, Guillier M, Lenormand J-L, Leibovitch M-P (1993) P34 ${ }^{\mathrm{cd} 2}$ protein is complexed with the $\mathrm{c}$-mos protein in rat skeletal muscle. Oncogene 8:236l-2369.

Leterrier J-F, Liem RK, Shelanski ML (1981) Preferential phosphorylation of the 150,000 molecular weight component of neurofilaments by a cyclic AMP-dependent, microtubule-associated protein kinase. J Cell Biol 90:755-760.

Leterrier J F, Liem RKH, Shelanski ML (1982) Interaction between neurofilaments and microtubule-associated proteins: a possible mechanism for intraorganellar bridging. J Cell Biol 95:982-986.

Lew J, Beaudette K, Litwin CME, Wang JH (1992a) Purification and characterization of a novel proline-directed protein kinase from bovine brain. J Biol Chem 267:13383-13390.

Lew J, Winkfein RJ, Paudel HK, Wang JH (1992b) Brain prolinedirected protein kinase is a neurofilament kinase which displays high sequence homology to P34cdc2. J Biol Chem 267:25922-25926.

Lew J, Huang Q-Q, Qi Z, Winkfein RJ, Aebersold R, Hunt T, Wang JH (1994) A brain-specific activator of cyclin-dependent kinase 5 . Nature 371:423-426.

Link WT, Grant P, Hidaka H, Pant HC (1992) Casein kinase I and II from squid brain exhibit selective neurofilament phosphorylation. Mol Cell Neurosci 3:548-558.

Link WT, Dosemeci A, Floyd CC, Pant HC (1993) Bovine neurofilament-enriched preparations contain kinase activity similar to casein kinase I-neurofilament phosphorylation by casein kinase I (CKI). Neurosci Lett 151:89-93.

Maniatis T, Fritsch EF, Sambrook J (1982) Molecular cloning: a laboratory manual. Cold Spring Harbor, NY: Cold Spring Harbor Laboratory.

Mantile G, Miele L, Cordella-Miele E, Singh G, Katyal SL, Mukherjee AB (1993) Human Clara cell 10-kDa protein is the counterpart of rabbit uteroglobin. J Biol Chem 268:20343-20351.

Mawal-Dewan M, Sen PC, Abdel-Ghany M, Shalloway D, Racker E (1992) Phosphorylation of tau protein by purified P34cice and a related protein kinase from neurofilaments. J Biol Chem 267:1970519709.

Miyakawa H, Okabe S, Ishiguro K, Uchida T, Hirokawa N (1993) Interaction of the tail domain of high molecular weight subunits of neurofilaments with the $\mathrm{COOH}$-terminal region of tubulin and its regulation by $\tau$ protein kinase II. J Biol Chem 268:22695-22702.
Moreno S, Hayles J, Nurse P (1989) Regulation of P34cai2 protein kinase during mitosis. Cell 58:361-372.

Myerson M, Enders GH, Wu C-L, Gorka C, Nelson C, Hariow E, Tsai $\mathrm{L}-\mathrm{H}$ (1992) A family of human ede2-related kinases. EMBO J 11: 2909-2917

Ookata K, Hisanaga S, Okumura E, Kishimoto T (1993) Association of $\mathrm{P} 34^{\mathrm{cdc} 2} /$ cyclin $\mathrm{B}$ complex with microtubules in starfish oocytes. J Cell Sci 105:873-881.

Pant HC, Gallant PE, Gainer H (1986) Characterization of a cyclic nucleotide- and calcium-independent neurofilament protein kinase activity in axoplasm from the squid giant axon. J Biol Chem 261:29682977

Paudel HK, Lew J, Ali Z, Wang JH (1994) Brain proline-directed protein kinase phosphorylates tau on sites that are abnormally phosphorylated in tau associated with Alzheimer's paired helical filaments. J Biol Chem 268:23512-23518.

Rialet V, Meijer L (1991) A new screening test for antimitotic compounds using the universal $M$ phase-specific protein kinase, P34 cyclin $\mathrm{B}^{\text {cal } 13}$, affinity-immobilized on P13 $3^{\text {suc }}$-coated microtitration plates. Anticancer Res 11:1581-1590.

Runge MS, Laue TM, Yphantis DA, Lifsics MR, Saito A, Altin M, Reinke K, Williams RC Jr (1981) ATP-induced formation of an associated complex between microtubules and neurofilaments. Proc Natl Acad Sci USA 78:1431-1435.

Sacher MG, Athlan ES, Mushynski WE (1992) Okadaic acid induces the rapid and reversible disruption of the neurofilament network in rat dorsal root ganglion neurons. Biochem Biophys Res Commun $186: 524-530$.

Sasse J, Gallagher SR (1994) Detection of protein. In: Current protocols in molecular biology, Vol 2 (Ausubel FM, Brent R, Kingston RE, Moore DD, Seidman JG, Smith JA, Struhl K, eds), pp 10.6.110.6.8. New York: Green/Wiley.

Schulze KL, Littleton JT, Salzberg A, Halachmi N, Stern M, Lev Z Bellen HJ (1994) rop, a Drosophila homolog of yeast Sec 1 and vertebrate $n-S e c$ 1/Munc- 18 proteins, is a negative regulator of neurotransmitter release in vivo. Neuron 13:1099-1108.

Serrano L, Diaz-Nido J, Wandosell F, Avila J (1987) Tubulin phosphorylation by casein kinase II is similar to that found in vivo. J Cell Biol 105:1731-1739.

Shetty KT, Link WT, Pant HC (1993) cde2-like kinase from rat spinal cord specifically phosphorylates KSPXK motifs in neurofilament proteins: isolation and characterization. Proc Natl Acad Sci USA 90 $6844-6848$.

Shetty KT, Kaech S, Link WT, Jaffe H, Flores CM, Wray S, Pant HC, Beushausen S (1995) Molecular characterization of a neuronal-specific protein that stimulates the activity of cdk5. J Neurochem 64 : 1988-1995.

Szaro BG, Whitnall MH, Gainer H (1990) Phosphorylation-dependent epitopes on neurofilament proteins and neurofilament densities differ in axons in the corticospinal and primary sensory dorsal column tracts in the rat spinal cord. J Comp Neurol 302:220-235.

Toru-Delbauffe D, Pierre M, Osty J, Chantoux F, Francon J (1986) Properties of neurofilament protein kinase. Biochem J 235:283-289.

Tournier S, Raynaud F, Gerbaud P, Lohmann SM, Dor'ee M, EvainBrion D (1991) Association of type II cAMP-dependent protein kinase with $\mathrm{P} 34^{\mathrm{cdc} 2}$ protein kinase in human fibroblasts. $\mathrm{J}$ Biol Chem 266:19018-19022.

Tsai L-H, Takahashi T, Caviness Jr VS, Harlow E (1993) Activity and expression pattern of cyclin-dependent kinase 5 in the embryonic mouse nervous system. Development 119:1029-1040.

Tsai L-H, Dellale I, Caviness VS Jr, Chae T, Harlow E (1994) p35 is a neural-specific regulatory subunit of cyclin-dependent kinase $5 . \mathrm{Na}-$ ture 371:119-123.

Way J, Hellmich MR, Jaffe H, Szaro B, Pant HC, Gainer H, Battey J (1992) A high-molecular weight squid neurofilament protein contains a lamin-like rod domain and a tail domain with Lys-Ser-Pro repeats. Proc Natl Acad Sci USA 89:6963-6967.

Wible BA, Smith KE, Angelides KJ (1989) Resolution and purification of a neurofilament-specific kinase. Proc Natl Acad Sci USA 86:720724

Yamashita M, Fukada S, Yoshikuni M, Bulet P, Hirai T, Yamaguchi A, Yasuda H, Ohba Y, Nagahama Y (1992) M-phase-specific histone H1 kinase in fish oocytes. J Biochem 205:537-543.

Zhou R, Daar I, Ferris DK, White G, Paules RS, Woude GV (1992) pp39 $3^{\text {mos }}$ is associated with $\mathrm{P} 34^{\text {cdc } 2}$ kinase in $\mathrm{c}-\mathrm{mos}^{\mathrm{xe}}$-transformed NIH 3T3 cells. Mol Cell Biol 12:3583-3589 